\title{
Locoweed Poisoning in Livestock
}

\section{By Daniel Cook, Michael H. Ralphs, Kevin D. Welch, and Bryan L. Stegelmeier}

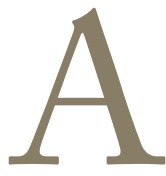

stragalus and Oxytropis species are members of the Legume family that occur throughout western North America and terrestrial ecosystems worldwide. In North America alone there are 354 known species of Astragalus and 22 species of Oxytropis. Most of these species are nontoxic and are important forages; however, several species are toxic to both livestock and wildlife. Historically toxic species are divided into three groups based on the toxic syndromes observed in livestock: 1) selenium poisoning, 2) nitrotoxin poisoning, and 3) locoism caused by the toxin swainsonine. Plant species associated with each toxic syndrome are listed in Table 1.

In North America approximately 25 seleniumaccumulating species occur in the taxonomic family Astragalus (Table 1). These plants grow in soils with high concentrations of selenium and are often used as indicators of selenium-rich soils. These indicator plants actively accumulate selenium as part of organic compounds. Though typically considered unpalatable to livestock, these plants may cause selenium poisoning. In addition, these plants may indirectly contribute to selenium poisoning by making inorganic selenium available in organic forms to more palatable adjacent forbs and grasses that can accumulate organic selenium.

Low-dose chronic selenium poisoning is often called alkali disease. Alkali disease manifests itself through loss of hair, lameness, loss of weight, and infertility. Acute selenium poisoning may occur within a few hours to a couple of days after an animal consumes a large quantity of a selenium-accumulating plant, such as Astragalus racemosus. Plants that cause acute selenium toxicity contain $100-8,000$ ppm selenium. The affected animal will emit a garlic-like odor on its breath and will stand with a lowered head and labored breathing. Eventually, if a sufficient amount of plant material is consumed, it will die of respiratory or circulatory failure.

Over 250 species and varieties of Astragalus in North America contain nitrotoxins (Table 1). However, most of these species are not associated with livestock poisoning because of their distribution and density. The toxic compounds are 3-nitropropanol, 3-nitropropionic acid, and their glycosides (miserotoxin). Poisoning causes a neurologic disturbance called "cracker heels" because the poisoned animals strike their hooves together when they walk as well as a respiratory disturbance called "roaring disease" due to breathing difficulties.

The third group and the principal focus of this paper is locoweed poisoning or "locoism," caused by Astragalus and Oxytropis species. "Loco" is a Spanish word for crazy. This term has been used by the people of North America for over a century to describe poisoned animals and the plants responsible for the poisoning. Locoism was first recognized in horses by De Soto and other Spanish explorers in the Southwestern United States. In the 1800s as settlers and stockmen moved west on the American frontier they encountered many poisonous plants, with locoweeds being one of the most widespread. During the early 1900s, livestock poisoning by locoweed reached a critical threshold such that the USDA Bureau of Plant Investigations established a research station at Hugo, Colorado, in 1905. C. D. Marsh conducted a series of feeding and grazing experiments demonstrating that Oxytropis and Astragalus species are the cause of locoism, while documenting the clinical symptoms of locoweed poisoning. His observations created a foundation for further research.

Locoweed poisoning is a significant problem in New Mexico, Colorado, Wyoming, Montana, Utah, and Texas, and to a lesser extent in other states in the western United States. Figure 1 shows major sites of locoweed poisoning as documented by the USDA-Agricultural Research Service Poisonous Plant Research Laboratory during the last 50 years. Locoweed poisoning is estimated to cause $\$ 100$ million in losses annually. It should be noted that locoism is not limited to North America; numerous Astragalus, Ipomoea, Oxytropis, Sida, Turbina, and Swainsona species contain swainsonine and poison livestock in Asia, Australia, and South America.

\section{Plant Ecology}

Astragalus and Oxytropis species occur throughout North America in a variety of vegetation types, including alpine 


\section{Table 1. Astragalus and Oxytropis species that commonly poison livestock in North America}

\section{Selenium-accumulating}

Astragalus albulus

\section{A. beathii}

A. bisulcatus

A. crotalariae

A. cutleri

A. debequaeus

A. drummondii

A. eastwoodiae

A. flavus

A. grayi

A. moencoppensis

A. nelsonianus

A. oocalycis

A. pattersonii

A. pectinatus

A. praelongus

A. racemosus

A. saurinus

A. sophoroides

A. toanus
Nitrotoxin (nitropropionic, nitropropanol)-containing

A. atropubescens

A. canadensis

A. convallarius

A. emoryanus

A. falcatus

A. miser var. hylophilus

A. miser var. oblongifolius

A. miser var. serotinus

A. pterocarpus

A. praelongus ${ }^{\mathrm{a}}$

A. tetrapterus

A. toanus

A. whitneyi
Locoweeds or swainsoninecontaining

A. allochrous

A. asymmetricus

A. bisulcatus

A. didymocarpus

A. drummondiia

A. emoryanus ${ }^{b}$

A. humistratus

A. lentiginosus

A. lonchocarpus

A. missouriensis

A. mollissimus

A. nothoxys

A. oxyphysus

A. praelongus ${ }^{\mathrm{a}}$

A. pubentissimus

A. purshii

A. pycnostachyus

A. tephrodes

A. thurberi

A. wootoni

Oxytropis besseyi

O. campestris

O. sericea

O. lambertii

Sources: Welsh et al. 2007; Williams and James 1978; Molyneux et al. 1989.

a Primary selenium accumulator.

b Primary nitrotoxin-containing plant.

tundra, deserts, grasslands, and open woods. The locoweeds are primarily found west of the Great Plains. Approximately 20 North American Astragalus and Oxytropis species are associated with locoweed poisoning or reported to contain the toxin, swainsonine (Table 1). A picture of the four major locoweed species, Astragalus lentiginosus, Astragalus mollissimus, Oxytropis sericea, and Astragalus wootoni, are shown in Figure 2. The distributions of these four major locoweed species, responsible for a significant portion of all poisonings, are shown in Figure 3.

Both Oxytropis and Astragalus locoweed populations fluctuate intermittently; however, observers have noted that
Oxytropis populations causing locoism tend to be more persistent than the Astragalus locoweeds. Many of the locoweed species occurring in drier environments experience extreme population cycles, increasing in wet years and declining during drought. Seeds predominantly germinate following autumn rains, with plants remaining green through the winter. They flower in the spring and may continue growing for 1-2 years. Seldom is precipitation adequate to sustain a significant population for more than three years.

Locoweeds are prolific seed producers with seeds remaining viable for multiple years because of their hard seed coats. Soil seed banks can range from 600 to 


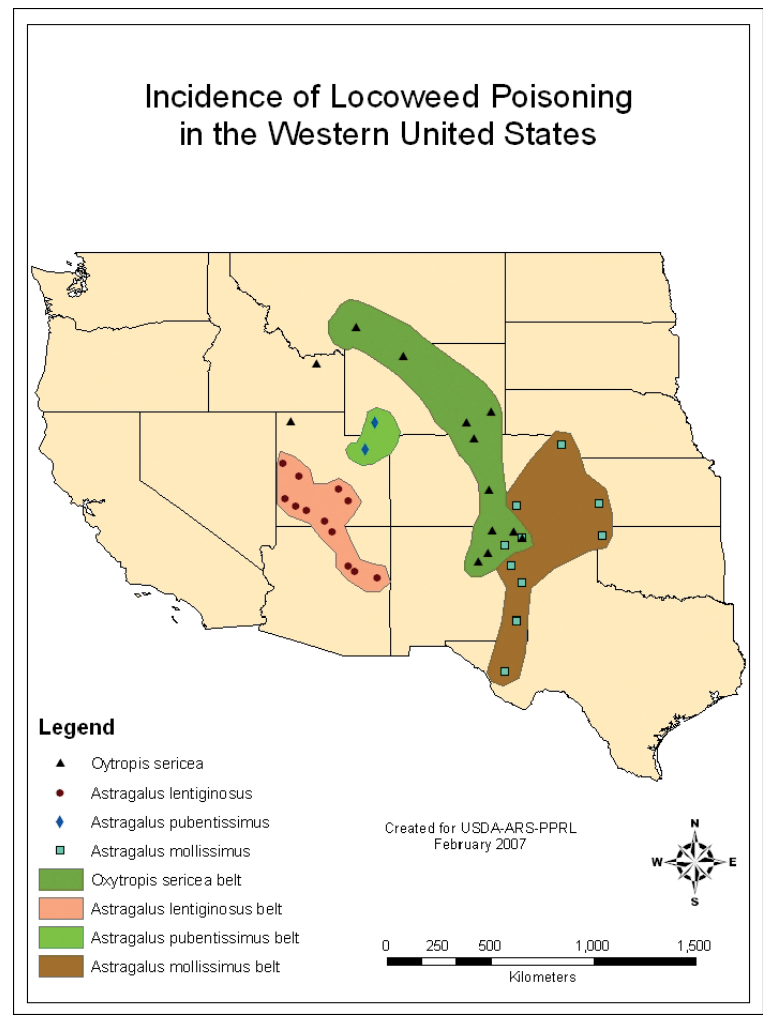

Figure 1. Sites of locoweed poisoning documented in the past half century at the USDA-Agricultural Research Service Poisonous Plant Research Laboratory.

4,000 seeds $/ \mathrm{m}^{2}$. Persistent seeds are an ecological advantage allowing locoweed seeds to remain dormant until conditions are favorable for germination and establishment. These seed bank dynamics are one reason that herbicide control may not be feasible.

\section{Toxin and Mechanism of Action}

The toxin in locoweed is swainsonine. Swainsonine was first identified in a legume from Australia, Srwainsona canescens, which causes a similar disease to locoism known as pea struck. Recently a fungal endophyte has been implicated in the synthesis of swainsonine. The fungal endophyte in locoweed grows in the plant without apparent effect to the plant. Furthermore, the endophyte is transmitted via the seed from generation to generation. So far the endophyte is found in all Astragalus and Oxytropis species that contain swainsonine.

Swainsonine inhibits several cellular enzymes called mannosidases by mimicking the sugar mannose. Mannosidases are important in the processing of oligosaccharides (complex carbohydrates or sugar polymers) and glycoproteins (proteins with attached sugars). Inhibition of $\alpha$ mannosidase by swainsonine results in the accumulation of complex carbohydrates and glycoproteins in the cell, causing cellular constipation and eventual cell death. In addition, inhibition of mannosidase II by swainsonine results in altered glycoprotein synthesis. Many of these incorrectly processed glycoproteins impair various cellular processes including cell-to-cell communication, cell movement, cellular adhesion, and intracellular trafficking. This ultimately affects multiple body systems including the reproductive, nervous, endocrine, and immune systems.

\section{Pathogenesis}

Locoweed poisoning has a subtle progression with few initial signs, eventually progressing to severe behavioral disorders. Even subtle signs may not be apparent until the animal has grazed the plant for several weeks. Marsh documented many of the clinical signs associated with poisoning, including a slow staggering gait, a rough hair coat, a staring gaze, emaciation, lack of muscular coordination, and extreme nervousness. Further research has shown that intoxication is initially characterized by depression, anorexia, and weight loss. Even at low doses of locoweed consumption in which animals appear clinically normal, animals can experience reduced weight gains compared to animals that did not consume locoweed. As animals become progressively intoxicated, they show more severe clinical signs, such as additional proprioceptive deficits, intention tremors, mild seizures, and nervousness. Chronically poisoned animals may exhibit some of the following clinical signs: a dull hair coat, decreased libido, infertility, abortion, water belly, cardiovascular disease, and death.

Nearly all animals can be poisoned by locoweed; however, animal species differ in their sensitivity. Horses are the most sensitive, followed by sheep, cattle, deer, and rodents. Differences in species susceptibility are poorly understood and are part of future research efforts. Animals may recover from locoweed intoxication; however, recovery is highly dependent on the severity of the poisoning. Most damage to cellular and bodily systems is reversible with time; however, brain damage may be permanent. This is evidenced by the observation that behavioral abnormalities often persist in animals even after animals have been removed from locoweed and apparent cellular damage has subsided.

\section{Reproductive and Other Effects}

Locoweeds negatively affect almost every aspect of reproduction in livestock. The effects of locoweeds on female reproduction are abnormal pituitary and ovarian function, delayed estrus, lengthened estrus cycles, altered oogenesis, delayed placentation, reduced placental and uterine vascular development, water belly (a reproductive abnormality), and abortion. Skeletal deformities, low vigor, and retardation in newborn animals are observed. Locoweeds affect male reproduction by reducing their libido and altering spermatogenesis. Most reproductive alterations are reversible; however, they can significantly impact livestock's reproductive fitness. Impaired spermatogenesis can be costly because producers may not realize that male infertility can 

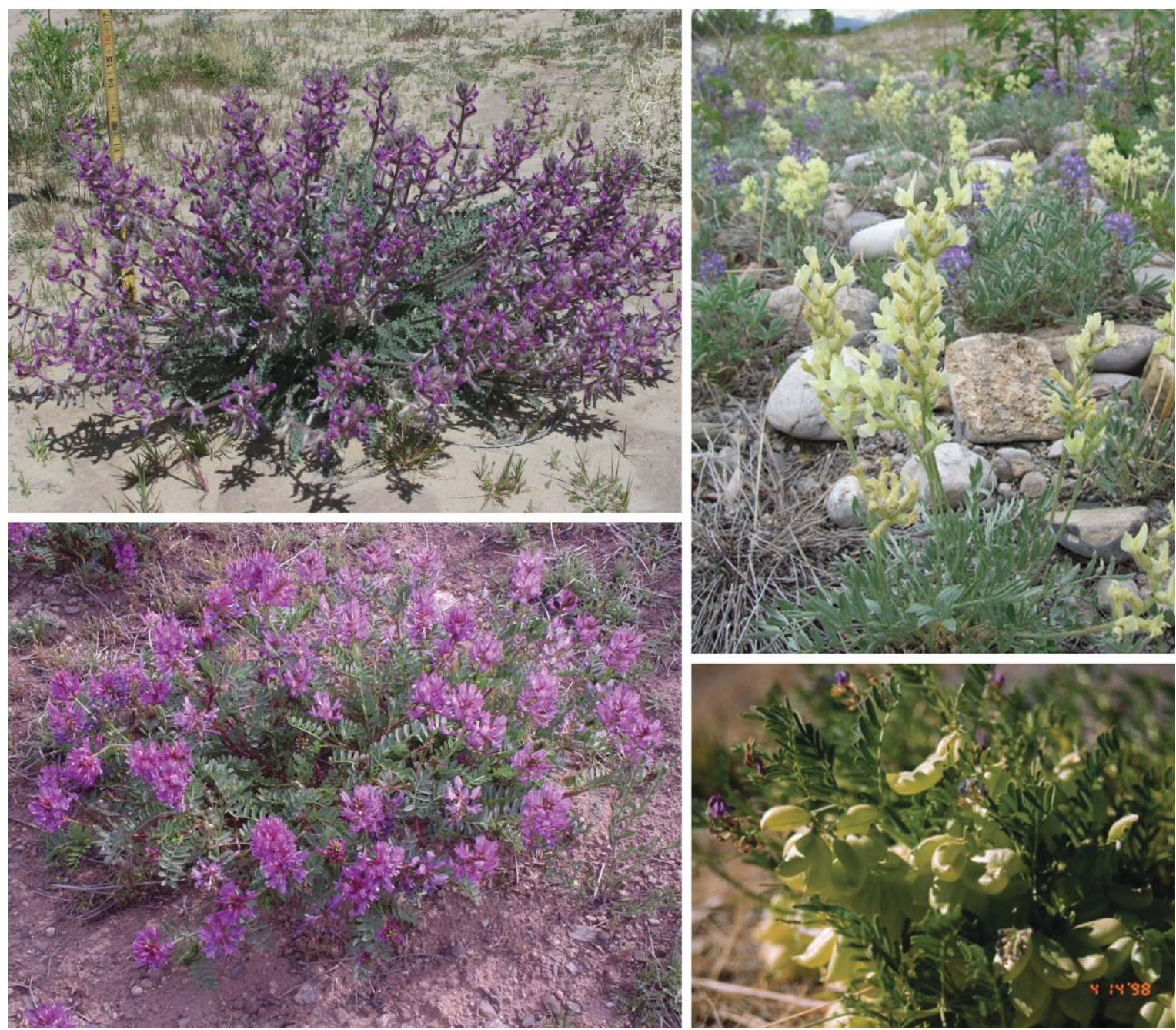

Figure 2. Four major locoweed species: (upper left) A. mollissimus, photo courtesy and copyright Al Schneider, www. swcoloradowildflowers.com; (lower left) A. lentiginosus; (upper right) O. sericea, photo courtesy of Heidi Hoerman; and (lower right) $A$. wootoni, photo courtesy of Texas toxic plants.

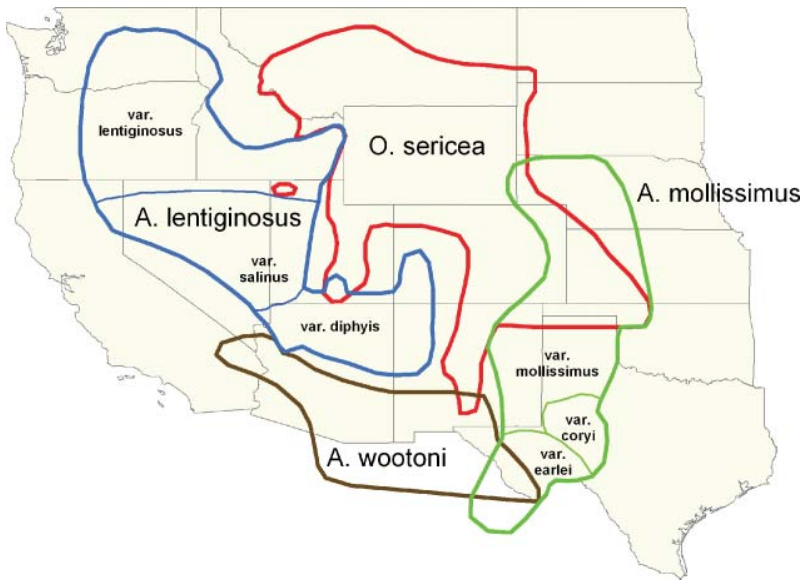

Figure 3. Distribution of the four major locoweed species and varieties.

occur for up to 90 days following locoweed consumption. Thus, conception rates can be disastrously low.

The mother-infant bond can be severely disrupted if locoweed is eaten by pregnant animals for an extended period. Affected females may be too nervous to allow offspring to suckle at birth. Furthermore, newborn animals lack vigor required to move and suckle normally and may not survive without assistance. If these intoxicated newborn animals survive, most behavioral deficiencies disappear before 9 months of age with no adverse effects on learning and diet selection. However, nursing animals may also be poisoned by their mother because swainsonine is readily excreted in milk, thus further intoxicating newborns.

\section{Diagnosis and Toxicokinetics}

Locoweed-induced poisoning is diagnosed by documenting exposure to the plant, identifying the characteristic clinical symptoms associated with poisoning, measuring blood or tissue swainsonine concentrations, and examining tissues of dead animals. Clearance studies have shown that swainsonine is rapidly absorbed, distributed, and excreted. Blood swainsonine concentration is limited in its usefulness as a diagnostic tool because of the rapid clearance of swainsonine to below-detectable concentrations. This is particularly a 
problem when animals may be exhibiting characteristic clinical signs of locoweed poisoning, yet no swainsonine can be found in the blood. Animals ingesting locoweed should be withheld from slaughter for 28 days after their last exposure to locoweed to ensure clearance of swainsonine from all tissues. Research is continuing on alternative diagnostic techniques to accurately diagnose and determine likely outcomes of locoweed poisoning in animals.

\section{Conditions of Grazing and Poisoning}

The single most important factor determining the severity of the disease state of a poisoned animal is the amount of plant material consumed over time. Like most forages the palatability of locoweed, or any other plant, is relative to the availability of other forages. Early reports of locoweed poisoning occurred when range conditions deteriorated because of overgrazing so that animals were forced to eat locoweed. Further studies by C. D. Marsh showed that animals started to eat locoweed early in the growing season when other forages such as grasses were still senescent. Research has demonstrated that the growth habit of a particular locoweed species generally determines which plants are eaten and how much they consume. For example, in the short-grass prairie, locoweeds begin to grow in the late fall and early spring, making them more palatable than the dry dormant grasses.

\section{Grazing Management Recommendations}

Grazing management can alter locoweed consumption since livestock use of locoweeds increases as more desirable forage becomes limiting. A number of management strategies are discussed further.

\section{Restrict Access}

The most effective grazing management strategy is to deny livestock access to locoweeds during periods when they are the most palatable and desirable forages are limiting. For example, on the short-grass prairies of northeastern New Mexico, cattle should not be put onto loco-infested rangelands until the warm-season grasses have started to grow in late May and early June. Locoweed-free pastures should be reserved for grazing for late winter and earlyto-mid-spring grazing to prevent locoweed poisoning.

\section{Do Not Overstock Locoweed-Infested Areas}

Rangelands with locoweed should not be overstocked, thus ensuring that adequate forage is available. An abundance of good forage and healthy range conditions will minimize poisoning by locoweeds. Grazing pressure can force cattle to begin eating locoweed. For example, rest-rotation grazing systems are not an effective tool where locoweed is present, because their intent is to get livestock to uniformly graze all forage in a pasture. However, a grazing system such as a three-herd four-pasture deferred rotation grazing system appears effective in limiting locoweed-induced poisoning. In addition, an on-off grazing system between pastures with and without locoweed is a possible solution to limit locoweed-induced poisoning. Careful selection of the proper grazing system in locoweed-infested ranges will minimize potential poisonings.

\section{Sort Out Animals That Graze Locoweeds}

Initial observations suggested that locoweeds were addictive because horses consumed more of it as they became intoxicated. However, current studies suggest that locoweed preference is a function of other available feeds and forages. Some animals seem to acquire a preference, or a taste, for locoweed and other swainsonine-containing plants (e.g., Ipomoea). These animals are often referred to as "locoeaters." This preference may be the result of bioactive secondary compounds in locoweed that provide positive reinforcement or positive sensations in the brain. These loco-eaters in a herd can influence others to eat locoweed through social facilitation and/or peer pressure. In some circumstances ranchers may remove loco-eaters from the herd to eliminate social facilitation and to prevent further intoxication. Some ranchers have had success in greatly reducing the numbers of poisoned animals by strictly culling any animal seen eating any locoweed; eventually these herds have been selected so that the remaining animals eat little or no locoweed.

\section{Herbicide Controls}

Locoweed species can be controlled using common rangeland herbicides. Some of the herbicides that were effective in controlling locoweeds are Tordon ${ }^{\mathrm{TM}}$, Grazon $\mathrm{PC}^{\mathrm{TM}}$, Stinger ${ }^{\mathrm{TM}}$, Curtail ${ }^{\mathrm{TM}}$, and Escort ${ }^{\mathrm{TM}}$. Heribicide control of locoweed in pastures can greatly reduce locoweed in pastures with dense stands of locoweeds during critical grazing periods. Selective herbicidal control on limited pastures (so-called loco-free pastures) may be economical, but general spraying on a large scale is not cost effective because of the residual seed in the soil.

\section{Train Animals to Avoid Locoweed}

Implementing conditioned-taste aversions is another method to prevent locoweed consumption in cattle. Using this technique animals associate the taste of the plant, for example, locoweed, with the stomach illness caused by a drug, lithium chloride, thus causing the animals to abstain from eating the plant. Some ranchers have had success using this labor-intensive technique. However, there are a number of items to consider. First, conditioning works best if the animals have not grazed locoweed previously. It is possible to avert loco-eating animals, but more than one dose of lithium chloride is often necessary, and the rate of success is diminished. Second, averted animals must be grazed separately from nonaverted animals because of social facilitation. Livestock graze in social groups, and nonaverted members of a group will influence averted animals to sample 
locoweed. Without negative reinforcement from lithium chloride locoweed aversions are extinguished.

\section{Future Directions}

Solutions to the locoweed poisoning problem are actively being pursued at the USDA-Agricultural Research Service Poisonous Plant Research Laboratory and by faculty at New Mexico State University. A multidisciplinary research team representing a number of scientific disciplines, including range science, chemistry, toxicology, plant physiology, and animal science, has provided research-based management strategies to diminish the locoweed problem.

The recent discovery of a fungal endophyte responsible for synthesis of the locoweed toxin swainsonine has created new opportunities to develop an array of new solutions. Research has shown that the endophyte is passed from seed to seed. Disruption of this process may be a solution to the locoweed problem. In addition, studies are being pursued to identify physiological markers such as a protein or a metabolite that are diagnostic of locoweed intoxication. After a marker has been identified, further studies will be performed to determine whether it correlates with the severity of poisoning and/or if it provides information regarding the animals' potential to recover from toxicosis. The hope of this research is to provide diagnostic tools that can be used to identify poisoned animals, determine the level of intoxication, make rational decisions on marketing, treatment, and disposition of poisoned animals, and determine the risk of feed and food contamination.

\section{Summary}

Rangelands serve as a source of high-quality animal feed despite the presence of poisonous plants. Development of strategies to minimize the negative impact of poisonous plants will improve rangeland productivity by minimizing death losses and poor animal performance. Locoweed poisoning is the most widespread poisonous plant problem in the western United States, and throughout the world.
This review has highlighted how research has provided strategies helping to minimize the locoweed problem.

\section{Additional Reading}

Burrows, G. E., and R. J. Tyrl. 2001. Toxic plants of North America. Ames, IA, USA: Iowa State University Press. p. 510-535, 594-599.

Molyneux, R. J., L. F. James, K. E. Panter, and M. H. Ralphs. 1989. The occurrence and detection of swainsonine in locoweeds. In: L. F. James, A. Elbein, R. J. Molyneux, and C. D. Warren [EDs.]. Swainsonine and related glycosidase inhibitors. Ames, IA, USA: Iowa State University Press. p. 100-117.

Panter, K. E., L. F. James, B. L. Stegelmeier, M. H. Ralphs, AND J. A. Pfister. 1999. Locoweeds: effects on reproduction in livestock. Journal of Natural Toxins 8:53-62.

Ralphs, M. H. And L. F. James. 1999. Locoweed grazing. Journal of Natural Toxins 8:47-51.

Stegelmeier, B. L., L. F. James, K. E. Panter, M. H. Ralphs, And D. R. Gardner. 1999. The pathogenesis and toxicokinetics of locoweed (Astragalus and Oxytropis spp.) poisoning in livestock. Journal of Natural Toxins 8:35-45.

Welsh, S. L., M. H. Ralphs, K. E. Panter, J. A. Pfister, and L. F. James. 2007. Locoweeds of North America: taxonomy and toxicity. In: K. E. Panter, T. L. Wierenga, and J. A. Pfister [EDs.]. Poisonous plants: global research and solutions. Wallingford, United Kingdom: CABI. p. 20-30.

Williams, M. C., And L. F. James. 1978. Livestock poisoning from nitro-bearing Astragalus. In: R. F. Keeler, K. R. Van Kampen, and L. F. James [EDS.]. Effects of poisonous plants on livestock. New York, NY, USA: Academic Press. p. 379-390.

Authors are Plant Physiologist, daniel.cook@ars.usda.gov (Cook), Rangeland Scientist (Ralphs), Toxicologist (Welch), and Veterinary Pathologist (Stegelmeier), Poisonous Plant Research Laboratory, Agricultural Research Service, United States Dept of Agriculture, 1150 E 1400 N, Logan, UT 84341, USA. Published with the approval of the Director as Journal Paper No. 8040 of the Utah Agricultural Experiment Station. 